\title{
Correction to: Periodontitis and Rheumatoid Arthritis: The Common Thread
}

\author{
Namrata S. Jajoo ${ }^{1} \cdot$ Anup U. Shelke ${ }^{1} \cdot$ Rajat S. Bajaj $^{2} \cdot$ Vivek Devani $^{3}$ \\ Published online: 14 December 2021 \\ ○) Springer Science+Business Media, LLC, part of Springer Nature 2021
}

\begin{abstract}
The two immunoinflammatory disorders, rheumatoid arthritis (RA) and Periodontitis (PD) are characterized by synovitis, joint damage, and alveolar bone degradation, are triggered by certain inflammatory mediators and leukocyte invasion, respectively. Rheumatoid arthritis is an infectious disorder which attacks changed self-epitopes and thus affects $1 \%$ of the human population, whereas $11 \%$ of the worldwide population aged is afflicted by extreme periodontal diseases in which commensal microbes upon the tooth surface is substituted by dysbiosis of the bacterial community that facilitate chronic inflammatory periodontal tissue damage. Periodontitis and RA display similarities in terms of pathogenesis amid variations in aetiology; all diseases entail systemic inflammation fuelled by, degradation of connective tissue, pro-inflammatory cytokines, and bone deterioration. Both the disorders have significant serological, epidemiological, and therapeutic connections and also have some common risk factors like aging and smoking. Laboratory and clinical data supporting this correlation is addressed in this aetiology analysis and the possible pathways involved in connecting both the diseases i.e., periodontitis to RA are described.
\end{abstract}

$\begin{array}{ll}\text { Abbreviations } \\ \text { PD } & \text { Periodontitis } \\ \text { AMPAs } & \text { Anti-modified protein antibodies } \\ \text { ACPAs } & \text { Anti-citrullinated protein antibodies } \\ \text { DMARDs } & \text { Disease-modifying anti-rheumatic drugs } \\ \text { COX } & \text { Cyclooxygenase } \\ \text { PAD } & \text { Peptidylarginine deiminases } \\ \text { LPS } & \text { Lipopolysaccharides }\end{array}$

The original article can be found online at https://doi.org/10.1007/ s12018-020-09271-6.

Namrata S. Jajoo

namratajaju3010@gmail.com

$1 \quad$ MDS in Periodontics, Dr. Hedgewar Smruti Rugna Seva Mandal's Dental College and Hospital, Hingoli, Maharashtra 431513, India

2 MDS in Orthodontics, Vidya Shikshan Prasarak Mandal's Dental College and Research Centre, Nagpur, Maharashtra 440001, India

3 MDS in Periodontics, Pacific Dental College \& Hospital, Airport Road, Debari, Udaipur, Rajasthan 313024, India

\section{Introduction}

An autoimmune disorder, Rheumatoid arthritis (RA), is an inflammatory condition marked by persistent inflammation of the joints, with gradual deterioration leading in varying extents of disfigurement and physical impairment, especially in the minor hand and feet joints. Inflammation serves a vital component in the history of RA [1]. In an 1800 ph.d. research by a French medical student, Landre-Beaurais, who named it the "Primary aesthetic Gout" rheumatoid arthritis was first identified medically. The difference amongst gout and rheumatoid arthritis was eventually developed by Sir Alfred Garred in 1859 and he named the disease rheumatoid arthritis [2].

A disorder characterized by chronic inflammation that occurs due to the accumulation of bacteria is Periodontitis (PD). The bacteria accumulate between the gingiva and teeth. This accumulation is facilitated by various factors like smoking, host inflammatory reactions and genetic factors. Snyderman and McCarty were the $1^{\text {st }}$ ones to identify the PD and RA's common features in 1982. Many research evidence is then collected, which assist this similarity between the two disorders [3].

The related sequence of periodontitis and RA in biological sciences gives valuable information into these disorders. In both disorders, the host reaction, determined by immunogenetics, primarily dictates chronic inflammation. In addition, in 
both periodontitis and RA, the cells, cytokines, and enzymes that decide the degree of tissue damage exhibit a similar pathological sequence [4]. Ultimately, management techniques targeted at modulating these responses are identical because of common mutual pathological conditions. The emphasis of this analysis is on the contribution of oral disease, especially, oral bacteria, and periodontal disease to RA growth.

\section{Classification Criteria of Rheumatoid Arthritis (RA)}

New classification standards were adopted in 2010 by the European League Against Rheumatism (EULAR) and American College of Rheumatology (ACR) for Rheumatoid Arthritis. The latest criteria are not a diagnosis criterion, but a classification criterion for the detection of diseases with a strong risk of a chronic type emerging. [73] Furthermore, an individual diagnosed with RA is identified as having a score of 6 or greater. The "old" ACR standards of 1987 were overruled by these current inclusion parameters and were modified for early RA detection. The 'new' criterion for diagnosis, issued collectively by the European League Against Rheumatism (EULAR), and the American College of Rheumatology (ACR) set a point score between 0 and 10 . In the evaluation, four regions are protected [74] (Table 1).

Autoimmune and serology diagnostics hold considerable weight in the "new" guidelines since ACPA diagnosis is sufficient to identify the condition in an initial stage before joint damage happens. A major aspect of the 1987 ACR criterion was the deterioration of the joints seen in radiological pictures. [75] (Table 2) This requirement is no longer known to be important since it is merely the sort of harm that therapy is supposed to prevent.

\section{Etiology of Periodontitis and Rheumatoid Arthritis}

\section{Etiology of Periodontitis}

PD occurs by bacterial oral microbiome imbalance, mainly due to the 'red complex' that comprises Tannerella forsythia, Treponema denticola, and P. gingivalis [5]. In the heterogeneous microbiota found at the enamel surface, the red complex bacteria, together with Aggregatibacter actinomycetemcomitans, are unwelcome guests. The normal distance between the tooth and the underlying gum tissue aims to accomplish secure gingival sulcus colonization, disrupting the balanced population of commensal bacteria, contributing to the transfer of microbiome and stimulating the innate immune response reaction of the host [5]. Consequently, the bacteria are prone to assault by bactericidal peptides, proteins, phagocytic cells, and ROS. The effects of periodontal inflammation in the form of overactive neutrophils and elevated amounts of inflammatory molecules (like CRP and cytokines) may be established in the blood of patients with periodontitis, [6].
Table 1 The 2010 American College of Rheumatology/ European League Against Rheumatism classification criteria for RA

\begin{tabular}{ll} 
Target population (Who should be tested?): Patients who & Score \\
1) have at least 1 joint with definite clinical synovitis (swelling) & \\
2) with the synovitis not better explained by another disease Classification criteria for RA (score- \\
based algorithm: add score of categories A-D; a score of $\geq 6 / 10$ is needed for classification of a \\
patient as having definite RA) $\neq$ \\
A. Joint involvement§ & \\
1 large joint & 0 \\
$2-10$ large joints & 1 \\
$1-3$ small joints (with or without involvement of large joints) & 2 \\
$4-10$ small joints (with or without involvement of large joints) & 3 \\
$>10$ joints (at least 1 small joint) & 5 \\
B. Serology (at least 1 test result is needed for classification) & \\
Negative RF and negative ACPA & 0 \\
Low-positive RF or low-positive ACPA & 2 \\
High-positive RF or high-positive ACPA & 3 \\
C. Acute-phase reactants (at least 1 test result is needed for classification) & \\
Normal CRP and normal ESR & \\
Abnormal CRP or normal ESR & 0 \\
D. Duration of symptoms & 1 \\
$<6$ weeks & \\
$\geq 6$ weeks & 0 \\
\hline
\end{tabular}


Table 2 The 1987 revised criteria for the classification of rheumatoid arthritis (traditional format)*

\begin{tabular}{ll}
\hline Criterion & Definition \\
\hline $\begin{array}{l}\text { 1. Morning Stiffness } \\
\text { 2. Arthritis of } 3 \text { or more joint areas }\end{array}$ & $\begin{array}{c}\text { Morning stiffness in and around the joints, lasting at least } 1 \text { hour before maximal improvement. } 3 \text { joint areas simultaneously have had soft tissue swelling or fluid (not bony overgrowth alone) } \\
\text { observed by a physician. The } 14 \text { possible areas are right or left PIP, MCP, wrist, elbow, knee, ankle, and } \\
\text { MTP joints. }\end{array}$ \\
$\begin{array}{l}\text { At least } 1 \text { area swollen (as defined above) in a wrist, MCP, or PIP joint. } \\
\text { 3. Arthritis of hand joints }\end{array}$ & $\begin{array}{l}\text { Simultaneous involvement of the same joint areas (as defined in 2) on both sides of the body (bilateral } \\
\text { involvement of PIPS, MCPs, or MTPs is acceptable without absolute symmetry). }\end{array}$ \\
$\begin{array}{l}\text { 5ubcutaneous nodules, over bony prominences, or extensor surfaces, or in juxta-articular regions, observed } \\
\text { by a physician. }\end{array}$ \\
$\begin{array}{l}\text { Demonstration of abnormal amounts of serum rheumatoid factor by any method for which the result has } \\
\text { been positive in 4\% of normal control subjects. }\end{array}$ \\
$\begin{array}{l}\text { Radiographic changes typical of rheumatoid arthritis on posteroanterior hand and wrist radiographs, which } \\
\text { must include erosions or unequivocal bony decalcification localized in or most marked adjacent to the } \\
\text { 7. Radiographic changes }\end{array}$
\end{tabular}

*For classification purposes, a patient shall be said to have rheumatoid arthritis if he/she has satisfied at least 4 of these 7 criteria. Criteria 1 through 4 must have been present for at least 6 weeks. Patients with 2 clinical diagnoses are not excluded

\section{Etiology of RA}

It is a widespread autoimmune condition affecting mainly the joints and marked by persistent, debilitating joint inflammation, weakness, and high mortality rates that impact up to $0.5-1.0$ percent of the worldwide population [7]. While the reason of RA remains ill-defined, it is assumed to be induced by a mixture of environmental and genetic influences that contribute to the failure of immunity resistance in mucosal surfaces particularly in the periodontium, gut and lungs [8]. Autoimmune reaction is associated with the development of anti-citrullinated protein antibodies (ACPAs) and rheumatoid factor [9] that attach to citrullinated joint epitopes and contribute to the creation of rheumatoid factor-containing immune complexes that facilitate tissue harm by stimulation of dendritic cells and synovial macrophages and the secretion of tissue degrading enzymes and pro-inflammatory cytokines [10]. Peptidylarginine deiminases (PADs) that are produced by neutrophils through necrosis or during the formation of extracellular traps of neutrophils often citrulline proteins in the joints, resulting in a localized immune response that is self-supporting [11].

\section{How does RA happen?}

\section{Post-Translational Protein Modification}

The ACPAs invention redefined RA diagnosis. RA antibodies are highly correlated with substantial environmental and genetic factors that signify microbial participation. Antibodies are observable in circulation $<10$ years previous to the clinical manifestations of RA [12], suggesting the premature lack of tolerance to citrullinated proteins could be attributable to the results of an inflammatory incident arising beyond the joint.
However, most proteins in our body undergo some type of post-translational alteration that is necessary for the proper working of bodies, like lipidation, glycosylation, or proteolytic processing. These alterations can contribute to the genetic eradication of anti-modified protein antibodies (AMPAs), including ACPAs in persons who are genetically prone to particular environmental exposures. Numerous AMPAs are correlated with RA and ACPAs, namely autoantibodies that interact with the fractured IgG hinge area and autoantibodies that identify traces of malondialdehyde-acetaldehyde-modified lysine, carbamylated and acetylated, in protein molecules [13].

\section{Citrullinated Proteins}

Citrullination arises spontaneously in vivo and plays an essential part in the proper working of the immune response as well as in physiological mechanisms like skin keratinization, neuronal axon separation, plasticity preservation in the CNS, and chromatin remodelling in gene regulation. The posttranslational protein alteration through the enzymatic decrease of arginine residues turns these positively charged residues into a neutral residue of citrulline [14]. In addition, arginine residue decrease will arise under pathological inflammatory disorders correlated with neutrophil necrosis and apoptosis [15].

Citrullinated proteins can be present in distressed lungs [16], in inflamed periodontitis patients [17], and in the gut [18]. Relative to normal people, the degree of citrullination of protein is elevated in the digestive tract of patients with RA [18]. In comparison, hypercitrullination in the gums has been correlated with A. actinomycetemcomitans are correlated with smoking in the periodontal pockets [19] and that in the lungs, therefore connecting this environmental factor to the development of ACPA [16]. These results suggest that citrullination happens at various locations in the body and reinforces the 
hypothesis that microbial inflammatory reactions can be triggered at locations other than the joints.

\section{Protein Citrulination by PADs}

The 'cornerstone' of RA pathogenesis is the catalysis of protein citrullination by endogenous PADs. $\mathrm{n}$ individuals and, other animals 5 PADs have been established, with distinct tissue distribution [20]. PAD1 and PAD3 are located in the hair follicles and epidermis, whereas PAD2 is distributed across the body in a number of tissues, namely haematopoietic cells, brain, and skin. PAD4 (previously named as PAD5) is mostly present in haematopoietic cells, and PAD6 is represented in the thymus, early embryos and ova [20]. PAD2 and PAD4 need extremely high in vitro active calcium concentrations $(>5 \mathrm{mM})$ [21], which is $3-5$ folds higher as compared to those present in synovial fluid and plasma [22].

PADs thus serve a crucial function in RA pathophysiology where enhanced protein citrulline in a cytokine-rich, inflammatory setting ultimately contributes to the degradation of the immunity of particular HLAs to citrullinated epitopes [23].

\section{Could Periodontal Pathogens be Involved in the Development of RA?}

Microorganisms which are correlated with periodontitis may even display several of the features that micro-organisms show in attempt to cause RA in a genetically prone organism. Periodontal infections are coordinated alongside certain classes of microbes in a biofilm and can be capable of inciting persistent chronic infection. In most people struggling from diverse types of periodontal disorder, potential periodontal infections were found frequently to be present. The biofilm in periodontitis acts as an excessive lipopolysaccharide (LPS) source, thus conveniently satisfying the forth chronic LPS sensitivity criterion. In addition, local development of $\operatorname{IgM}$ and $\operatorname{Ig} \mathrm{A}$ in periodontitis was illustrated, but it has not been expressed that the LPS from the periodontal biofilm is capable of cross-reacting with the cartilage to induce an anti-cartilage reaction [24].

\section{Role of Genetics in RA and Periodontitis}

Genetic factors are of significant importance in both PD and RA. Both display considerable heterogeneity in the clinical presentation of the condition that can be controlled for by genetic factors [34]. These variations in the disease manifestation are due to the over-expression or under-expression of various cytokines and other mediators of inflammation. Of these, it was observed that PGE2, TNF-alpha, and IL-1 are under very close genetic regulation. Researches focused on the overproduction of "hyper-responsive genetic monocyte traits" have shown common genetic origin influencing the vulnerability to autoimmune disorders, especially proinflammatory mediators like PGE2, TNF-alpha, and IL-1 usually seen in patients with severe periodontitis [35]. RA has also been identified as a monocytic hypersecretory condition [36].

The human leukocyte antigen D-related (HLA-DR) portion of chromosome 5 in the TNF- $\beta$ genes zone has been mapped to several of the genes that control the cytokine profiles and monocyte responses [37]. both RA and PD have been identified with this HLA complex; there is a general genetic explanation for the monocyte trait observed, connecting both PD and RA.

\section{Mechanism Linking Periodontitis to RA}

The relationship among RA and PD has been widely analysed. They are believe to correlate to several of the specific traits like environmental and genetic risk factors, such as smoking, HLA-DRB1 expression, and several other exogenous lifestyle factors like psychological factors (like stress), socioeconomic status, and diet, that eventually lead to gradual bone destruction [25-27].

During the 19th century, bacterial intervention in RA pathophysiology was first proposed; but, several groundbreaking developments were seen in recent years that bacterial dysbiosis at mucous membranes can cause a sequence of activities that contribute to whole grown rheumatoid arthritis. In the gut with a dysbiotic microbiota, or in the lungs of tobacco smokers citrullination combined with bacterial immune reactions may (eventually) contribute to a weakening of immune tolerance and enhanced development of ACPA initiate the pathophysiology of RA by several years [33].

Important risk variables in $\mathrm{PD}$ and $\mathrm{RA}$ development are the presence of A [8]. actinomycetemcomitans and P. gingivalis as microbiota in the gut and gums. Enhanced immune responses in RA to ACPA levels and P. gingivalis have been found in stable persons that grow RA at a future point (socalled 'pre-RA') [28, 29]. In 2015, Nagahama, who recorded a link among ACPAs and PD parameters (like the number of broken teeth, population clinical attachment loss and periodontal index) in 9,554 healthy adults, accepted this hypothesis [30].

The inflammatory state of joints is affected by P. Gingivalis by disturbing the local immune action of periodontium. At the site of periodontitis, A. actinomycetemcomitans, bacterially secreted leukotoxin, are specifically accounted for the release of hypercitrullinated substances from neutrophils, and these bacteria-specific antibody titres (and toxin 
itself) are closely correlated with the existence of rheumatoid factor and ACPA in RA patients [19] (Fig. 1).

These several evidences clearly emphasize the significance of PD in the development of ACPA and suit very well in the pathophysiologic model of 'two hit'. As per this model, connective tissue-destructive and bone diseases occurring over one region (e.g., postmenopausal osteoporosis skeletal system, joints in patients with RA etc.) can interact with periodontium tissues (the 2 nd hit) along with pathogenic microbe compounds (e.g., endotoxin) formed by subgingival biofilm (the 1st hit) (Fig. 2). This breakdown is well supported in resistance in periodontal tissues owing to PPADdependent or PAD-dependent citrullination [32].

\section{Vascular Alterations}

Current researches have indicated a common mechanism in the progression of RA and PD into the interaction among vascular injury and osteoclast activation. It's been proposed that both PD and RA share similar molecular mechanisms inside the Kappa $\beta$ (RANK)/osteoprotegerin (OPG) receptor activator/tumour necrosis key element apoptosis-inducing ligand (TRAIL) axis, contributing to decreased vascular defence due to a reduction in OPG [38, 45]. Moreover, rises in TRAIL and RANK levels inside inflamed tissues can contribute to the potential production of vascular injury and even to osteoclastic stimulation and eventual resorption of the bone.

A whole other vascular model suggests that one of the first phases of a variety of chronic disorders, like RA and PD, is microvascular involvement [39]. In this model, diminished capillary calibre is observed in both rheumatoid synovium and periodontal tissues along with larger amounts of blood vessels and extended capillaries.

\section{Bacterial Infection}

Certain periodontal bacteria display identical features to certain microbes accused of causing RA in a genetically vulnerable host. Periodontal microbes include LPS abundantly, that tends to cause constant systemic inflammation throughout periodontal tissues. It is also clinically appropriate that continuing periodontitis will cause or worsen genetically prone persons with RA. A variety of tests, like Aggregatibacter actinomycetemcomitans, Prevotella intermedia, Porphyromonas gingivalis, Bacteroides forsythus, and Prevotella melaninogenica have documented increased serum antibodies to a range of periodontopathic bacteria [40-43]. In synovial blood, increased antibodies to P. intermedia and B. forsythus have also been identified. Research documenting DNA for P. intermedia, T. Forsythensis, and P. gingivalis in synovial fluid of RA patients has provided additional proof for the function of periodontal pathogens in joint disease [44]. In the synovial fluid of non-rheumatoid patients, no DNA for these bacteria was identified [65].

\section{Chronic Inflammation}

The very famous hypothesis that links both the diseases is focused on the mutual etiology of them. Tooth plaques blamed for sustaining persistent periodontal inflammation [5] facilitate the aggregation of biofilm bacteria that stimulate Toll-like receptors (TLRs) in immune cells and identify pathogen-associated molecular patterns (PAMPs)
Fig. 1 A hypothetical "two-hit" model of induction of chronic destructive periodontitis. The first "hit" involves the periodontopathic subgingival biofilm and its microbial products, such as endotoxin. The second "hit" involves a medical systemic disease, such as (but not limited to) rheumatoid arthritis and post-menopausal osteoporosis, which increases biomarkers of systemic inflammation in the circulation, including $\mathrm{C}$ reactive protein (CRP), cytokines ( e.g., IL-6), prostanoids ( e.g. , PGE2), and matrix metalloproteinases (e.g., MMP9). CVD, Cardiovascular disease [31]

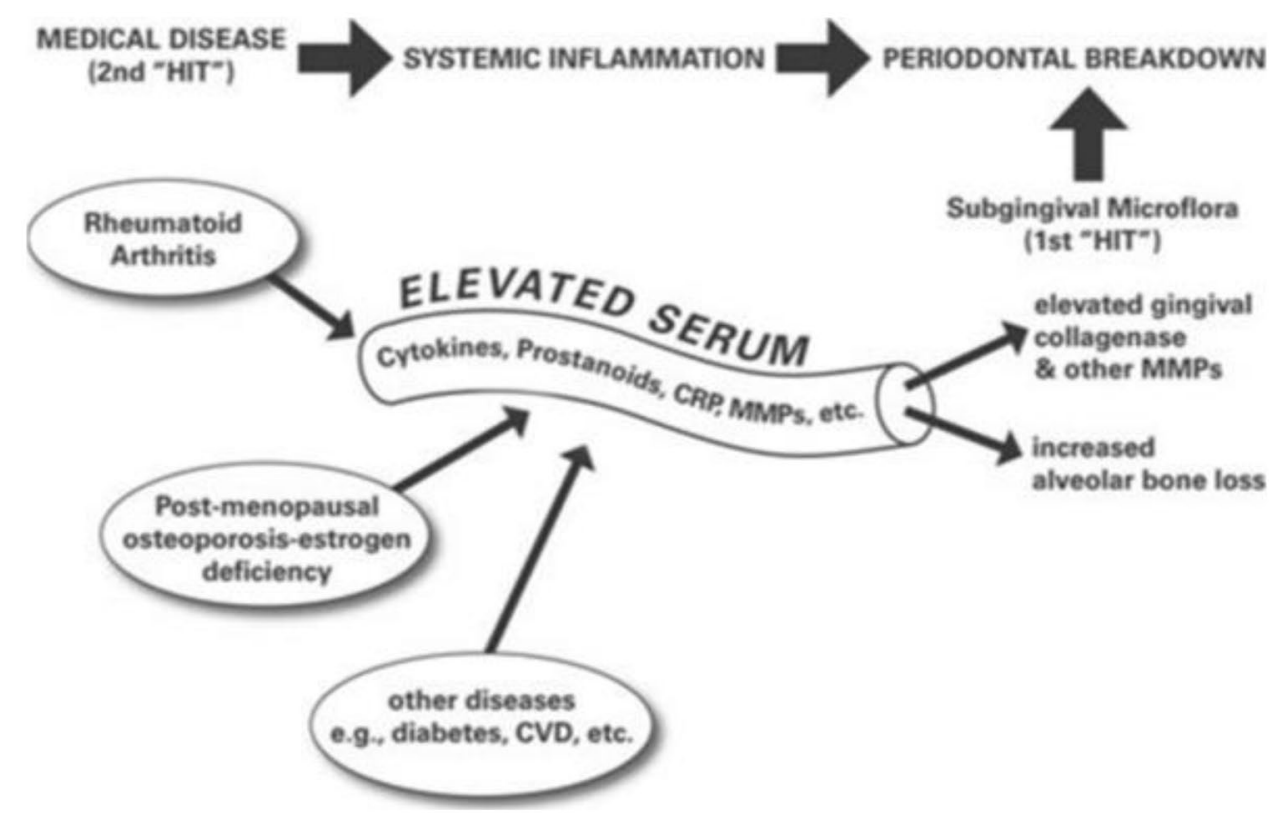




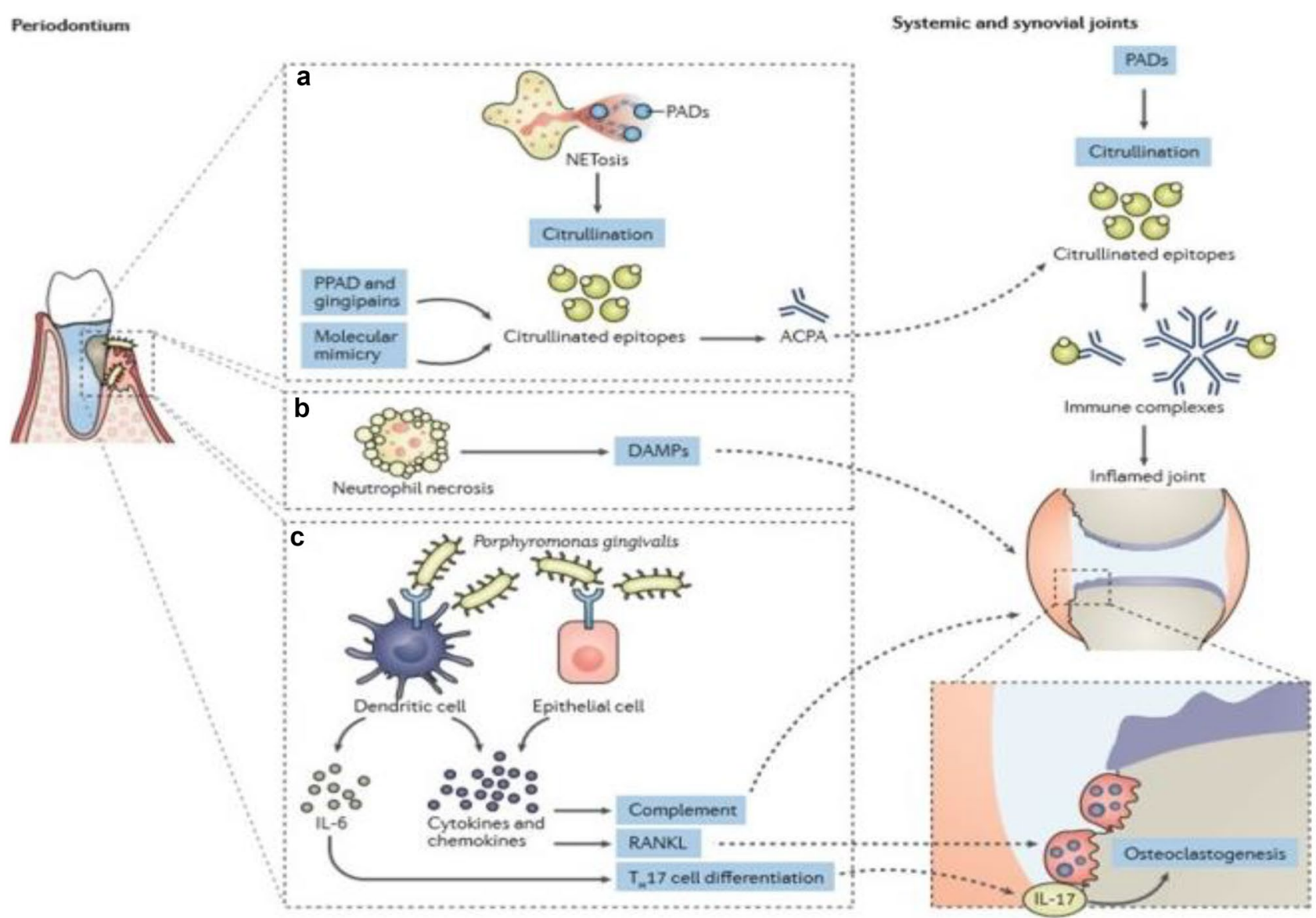

Fig. 2 Proposed mechanisms underlying the links between periodontal disease and the pathogenesis of rheumatoid arthritis [23] a In response to Porphyromonas gingivalis infection, neutrophils can release neutrophil extracellular traps (NETs), structures characterized by active proteases and peptidylarginine deiminases (PADs). The concomitant action of these enzymes generates citrullinated epitomes and triggers the synthesis of anti-citrullinated protein antibodies (ACPAs). The production of citrullinated epitomes is accelerated by the synergistic action of gingipains and P. gingivalis peptidylarginine deiminase (PPAD), both of which are unique to P. gingivalis. Molecular mimicry by some bacterial proteins (such as bacterial enolase with human $\alpha$-enoase) is also involved in the breakdown of immune tolerance to host molecules. A secondary signal directed against citrullinated epitopes in the joints leads to increased produc- tion of rheumatoid factor and ACPAs, leading to the accumulation of immune complexes. b Neutrophils attracted to the gingival crevice undergo necrosis, thereby releasing damage-associated molecular patterns (DAMPs), which accelerate local and systemic inflammation. c In the periodontium, virulence factors expressed by P. gingivalis, such as lipopolysaccharide, fimbriae, gingipains and lipoproteins, are recognized by Toll-like receptors, protease activated receptors and/ or nucleotide-binding oligomerization domain-containing 2 (NOD2) receptors on gingival epithelial cells and phagocytes, such as dendritic cells. in reponse to pathogens, the host cells release cytokines (such as IL-6) and chemokins that activate the complement system, receptors activator for nuclear $\mathrm{\kappa B}$ ligand (RANKL) signalling pathways and the differentiation of $\mathrm{T}$ helper cells, which contribute towards osteoclastogenesis in gingival epithelial cells and local phagocytes that trigger targeted release of pro-inflammatory cytokines. This chronic immune reaction has systemic effects, leading to elevated development of CRP and elevated serum concentrations of pro-inflammatory cytokines in PD patients [31].

$\mathrm{P}$. gingivalis seems to have a wide variety of PAMPs among periodontal pathogens, especially gingipains, fimbriae, and LPS that ensure the stimulation of a wide variety of immune receptors like proteinase-activated receptor 2 (PAR2), TLR4, TLR2, and nucleotide-binding domain-containing oligomerization protein 2 (NOD2) and clarify the superior function of $\mathrm{P}$. gingivalis in the production of inflammation [46]. Another cause for the epidemiological and clinical correlation among PD and RA may also be the aberrant activation of leukocytes and dysfunction of the cytokine network involved in the innate immune action to pathogenic bacteria.

The function of $\mathrm{T}$ cell specialization is well established as the biochemical connection among PD and RA. Cellrelated cytokines of TH17 are heavy arthritis inducers, and IL-17 is essential for the differentiation of osteoclasts and the growth of bone degradation. In the initial and productive phases of RA, the amount of TH17 cells was reported to rise; however, the root cause for this increment and PD was unclear [47]. 


\section{Anti-Citrullinated Protein Antibodies (ACPAs)}

Thus, persistent inflammation affects the immunity producing an atmosphere which is optimal for the deterioration of immune resistance. The operation of PADs is promoted by elevated levels of cell damage in inflamed tissue, combined with high levels of calcium ions. This operation of the enzyme, as well as the secretion of cellular proteins, leads in the immediate and unregulated production of citrullinated epitopes that, via the linking of ACPAs, cause autoimmune responses. This process establishes the biochemical foundation for connecting RA to PD. on patients with PD, ACPAs produced in the gingiva respond with citrullinated peptides in the joints that may develop after a traumatic event of joint [48]. Citrullination of autoantigens in synovial tissue as well as other mucosal locations, like the inflamed gingiva, is a precursor for inducing and sustaining autoimmune reactions in RA patients. Because the development of citrullinated epitopes depends on PADs, their significance is unquestionable in the generation of autoantigens that induce autoimmunity in RA [49].

\section{P. Gingivalis Peptidylarginine Deiminase (PPAD)}

The detection of PPAD, that is exclusively articulated by P. gingivalis, provided the best findings connecting PD to RA. The immune system is highly influenced by PPAD and can induce autoantigens' development, which drive RA autoimmunity [50]. PPAD action produces peptides and protein fragments combined with those of gingipains that are citrullinated at their C-terminus, which may reflect epitopes that are unique to the immune response. Periodontium PPAD activity is also elevated in RA patients and in people who do not have RA, but who do experienced periodontitis [51].

\section{Studies on Relationships Between Periodontitis and Rheumatoid Arthritis}

Till present, the relationship of PD and RA disorder has been investigated in only few researches and the findings have also been contradictory. For instance, Finnish research has shown little association among both diseases [52], although others indicate a higher incidence of RA periodontal bone loss. The absence of homogeneity in categorizing the distinct types of RA and periodontal disorder is a significant explanation for these differences. Many early research, indeed [53]. refused to take the distinct types of periodontal and RA disease into consideration and, as a consequence, grouped both subjects for more thorough analyses as either possessing periodontal disease or RA with little to no concern for subclassification. Given these limits, it is evident that the magnitude of the relationship between various types of periodontal and RA disease needs to be re-examined (See Table 3).

The incidence of mild to extreme PD was dramatically increased in patients with RA in the first pilot study exploring self-reported clinical encounter. Moreover, the opposite was also accurate and that, relative to the public at large, PD patients have a higher incidence of RA. [54].

65 patients visiting a rheumatology centre were tested for their PD and RA degree in the second pilot test. A monitoring category composed of citizens who did not have RA who were age and gender-matched. No variations were found among the control and RA groups for the bleeding and plaque indices. However, the RA sample did have slightly more teeth missing than the control group and relative to the controls, a higher proportion of both participants had wider pocketing. The proportion of reduction of alveolar bone associated favourably with the key RA intensity parameters [55].

Various essential results emerged from these 2 pilot tests. According to current dogma, RA patients should not have poor oral health (judged by bleeding and plaque scores). More interestingly, maybe, it has been known that persons with extreme RA were most prone to have severe PD and vice versa. While several RA patients are taking drugs that may mitigate periodontal devastation (i.e., immunosuppressants and NSAIDs), substantial periodontal degradation has been found in these patients. This suggests that PD was more likely to occur before the development of RA signs and was not observed. The period of the disease can also be a very significant consideration. Eventually, it is important to classify the disorder on the basis of seriousness and length in order to explain the interlinkages among RA and PD.

Additional data has currently been provided using an animal model to suggest an important association among RA and PD [56]. This research documented that the introduction of experimental rat arthritis (adjunctive arthritis) led to periodontal deterioration marked by alveolar bone degradation and enhanced matrix metalloproteinase development in adjacent gingivitis. Intriguingly, both of these responses happened without the subgingival or oral microflora being manipulated.

The underlying biological pathways are yet to be fully identified, considering all the data suggesting a correlation among PD to RA. Well-designed randomized, systematic multi-centre clinical studies with massive amounts of controls and some patients are required to properly explain the clinical interaction and the immunological and biochemical interplay among the two disorder. 


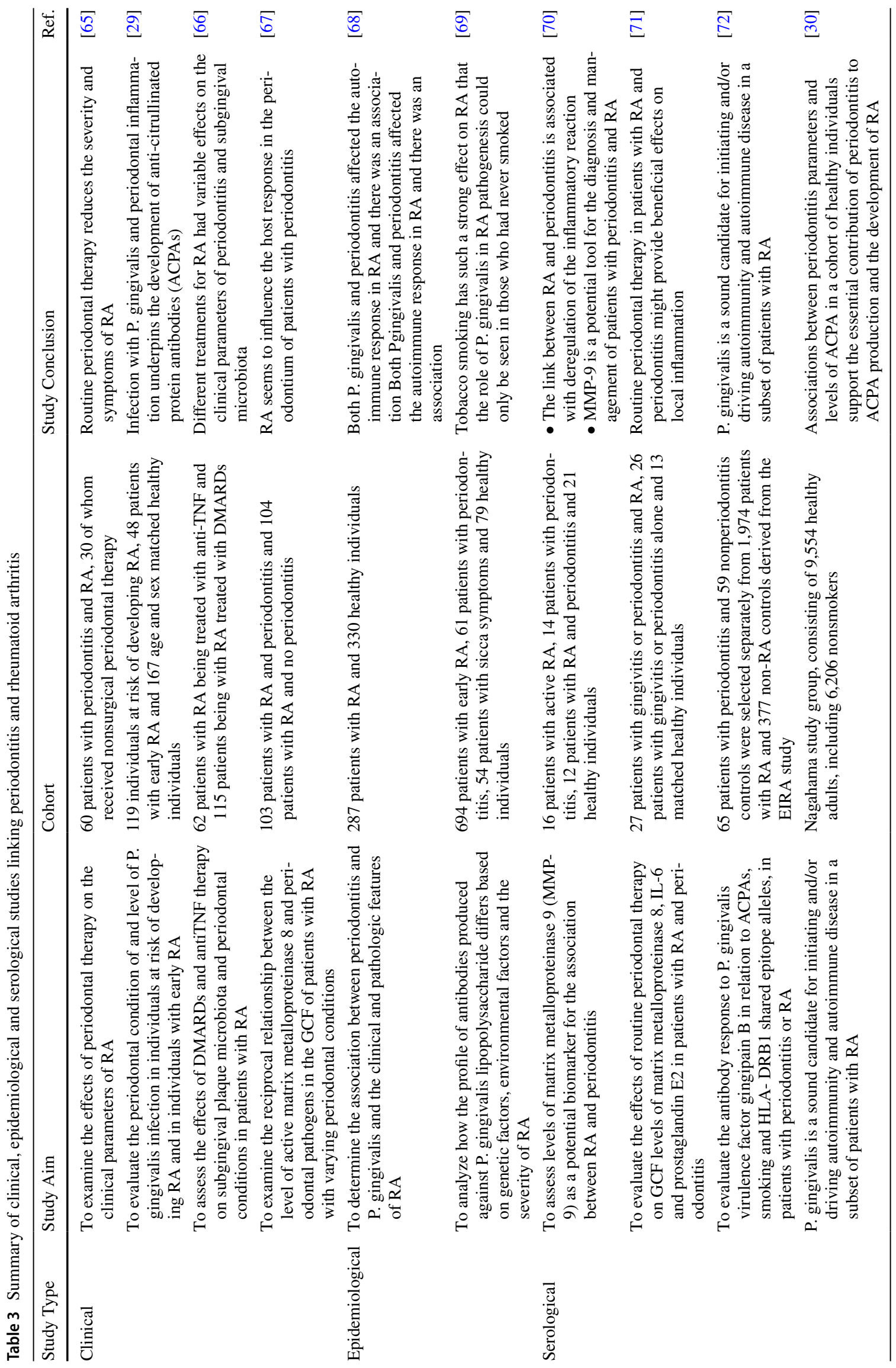




\section{Common Pathogenesis - Common Treatment?}

\section{Current and Emerging Therapies}

At present, NSAIDs like naproxen, aspirin, ibuprofen, and diclofenac remain the standard " first-line " care forms for RA. Both antipyretic and analgesic properties are generated by their mode of action by cyclooxygenase (COX) synthesis inhibition. Although these medicines are successful in decreasing RA discomfort symptoms, they do not modify their direction significantly [57]. Over the past 20 years, NSAIDs usage for the treatment of periodontal disorder has been researched. The extensive medicinal usage of these drugs to change the path of periodontitis is not standardized, but the indications seem positive. A "rebound" reaction to the baseline after the medication's termination [58] seems to be a specific concern with their usage for the treatment of PD.

A number of COX-2 blockers have been tested for their ability to avoid or slow down bone resorption with the identification of two COX enzymes essential for PGE2 development, named COX-1 (constitutively expressed) and COX-2 (inducible). Tenidap, was among the first COX-2 inhibitors created, was shown to suppress not just the development of PGE2 and COX, but also development of TNF-a, IL-6, and IL-1. naproxen (Naprosyn), Acetylsalicylate (Aspirin), etodolac (Lodine) and ibuprofen (Advil and Motrin) [76] are other NSAIDs employed as anti-inflammatory agents in RA. To present, COX-2 antagonists in periodontal disease have not been extensively examined for their ability to alter bone resorption.

Compared to NSAIDs, corticosteroids are much more active anti-inflammatory drugs, but they suffer with stronger adverse effects. For this function, at lower concentrations, throughout exacerbations or flares of RA, they are often recommended for a brief period of time. For localized inflammatory effects, intra-articular (IA) corticosteroid injections may be used [77]. They function by blocking the production of phospholipids and reducing the function of eosinophils, thereby reducing inflammation. Weight gain, Bone thinning, immunosuppression, and asthma are among their adverse effects. It may avoid thinning of the bone by encouraging individuals to take vitamin D and calcium supplements. By steadily tapering the doses, adverse effects may be minimized as the patient achieves progress. It is necessary not to withdraw oral or injected corticosteroids prematurely as it may contribute to repression of the rheumatoid arthritis flares or hypothalamic-pituitary-adrenal axis (HPA) [78].

A newest class of medicines known as disease-modifying anti-rheumatic drugs (DMARDs) has been created, unlike NSAIDs, that do not substantially alter RA's trajectory. The medicine must show the potential to alter the path of RA for at least 1 year in order to be listed as a DMARD, as demonstrated by continued progress in operation, reduced synovitis, and avoidance of further joint injury. Methotrexate, parenteral gold salts, hydroxychloroquine (anti-malarial drug), sulfasalazine, leflunomide, azathioprine, and penicillamine are examples of these drugs. An important downside to the usage of DMARDs is their severe toxicity. Owing to toxicity concerns, the usage of DMARDs for the treatment of PD has been generally limited. Nevertheless, the usage of gold salts in an animal model clearly shows decreased periodontal destruction [59].

Anti-rheumatic medications that alter biological disorders (bDMARDs) are very successful in delaying the worsening of joint injury induced by RA. While it is the best "simple, specified and targeted" type of care, it has several significant adverse effects including an elevated risk of lymphoma-like infections and multiple sclerosis and neurological disorder [79-81].

As an area of great promise, regulation of cytokines and their receptors is indeed increasing. For instance, two methods under study to amplify the influence of increased IL-1 in inflamed tissues are to block the IL-1 receptor and use gene therapy to produce an IL-1 receptor antagonist. Likewise, other research has also shown that RA patients, suppressing the action of another essential TNF-alpha, inflammatory cytokine, has clinical efficiency. In a primate model of PD, the functions of IL-1 and TNF antagonists have been shown to decrease inflammatory infiltrates in close proximity to the bone as well as to decrease osteoclastic development and decrease bone degradation [63].

One of the messenger proteins that promotes inflammation in the joints is tumour necrosis factor (TNF). The TNFinhibitors are biologic medicines like infliximab (Remicade), etanercept (Enbrel), certolizumab pegol (Cimzia), golimumab (Simponi), and adalimumab (Humira). These blockers primarily prohibit cells that trigger diseases from being recruited and thereby cause rapid relief of symptoms. In conjunction with many other DMARDs, especially Methotrexate, these medications are sometimes used. In patients with coronary artery disease from demyelinating disorders, TNF inhibitors are contraindicated [82-84]

A subcutaneously injected medicatiolower reaction rate than other biologicsn is Anakinra (Kineret) which is injected every day and acts by connecting to another chemical inflammatory messenger, interleukin 1 (IL-1). It can be used in conjunction with other DMARDs or monotherapy, although it is not commonly used since the medication has a $[85,86]$ Another drug Rituximab (Rituxan) is effective in RA because it depletes $B$ cells responsible for inflammation and irregular antibody development. When TNF-inhibitors have failed, this compound is predominantly used in RA. In 
two doses, it is given two weeks apart, every six months, as an intravenous infusion $[87,88]$

A biologic drug, Abatacept (Orencia), acts by preventing $\mathrm{T}$ cell activation. Administered predominantly by iv injection once every month or once every other week subcutaneously and is used in patients that have not been managed with conventional DMARD drugs effectively [89]. Another biologic that acts by suppressing interleukin 6 (IL-6) is tocilizumab (Actemra). It is provided by iv drip, given daily, or by subcutaneous weekly injections. It is often used in patients that have not been managed with conventional DMARD drugs effectively [90]. Finally, Tofacitinib (Xeljanz) is a JAK blocker that acts by suppressing Janus kinases within inflammatory enzyme cells. This drug is used in people that are not controlled with methotrexate adequately. Tofacitinib is taken individually or in conjunction with methotrexate, orally, twice a day. This drug should not be used in conjunction with conventional biologic drugs or other strong immunosuppressants [91, 92].

The regulation of matrix metalloproteinases (MMPs), which are essential intermediaries of connective tissue degradation in both soft and hard tissues, is another emerging field of interest for host regulation in PD and RA. In this context, a pathway that is independent of its antimicrobial property has been identified to suppress MMP action through tetracyclines and different chemical analogues [60]. A variety of clinical trials have been performed utilizing low-dose tetracycline to alter PD, with the latest evidence showing that low-dose doxycycline is secure and substantially effective [61]. Nevertheless, MMP inhibitors' function is less well known in the management of RA, but positive findings are evolving. A new analysis has found that when used adjunctly with methotrexate, reduced and higher dose doxycycline produces improved increases in global individual RA severity scores than methotrexate coupled with placebo [62].

All of these biologic agents addressing particular molecular processes correlated with chronic and acute inflammation have a tremendous potential to improve therapeutic results for both periodontal and RA disorder. Combination treatments that address different disease results are now evolving with the emerging awareness that PD and RA are multifactorial disorders. For example, in an animal trial, the application of a mixture of chemically processed tetracycline (CMT-1) with NSAID, like tenidap or flurbiprofen, has been documented to synergistically suppress extreme bone degradation in arthritic rats, suppressing the function of MMP in the joints. For periodontitis in humans, similar promising findings have been recorded [64].

Notwithstanding the above, it should be understood that, through recognizing that the subgingival biofilm is a primary etiological component, PD varies from RA in one major manner. No particular bacterial pathophysiology for RA has been established, unlike periodontal disease. Therefore, although PD is possible to alter the host disease mechanisms, the management of harmful bacteria that causes periodontal infections maintains a major priority for periodontal prevention and care. At all, just an adjunct therapy for should be PD the host alteration. Besides that, host alteration stays the recommended treatment before an etiological factor for RA can be identified.

\section{Conclusion}

In the last fifty years, intensive studies have been performed into the potential function of inflammation to cause disease growth in RA. Concrete proof has been elusive of a clear association between various chronic virus or bacterial infections and RA. Identification of the close interaction and possible pathogenicity of genetically defined immune responses to citrullinated peptides in RA has contributed with proof that persistent periodontal infection offers a persistent push for both citrullinated peptide development and immune activation. The theory that $\mathrm{P}$. gingivalis PPAD enzymes may result in the production of citrullinated bacterial peptides and citrullinated autoantigens specific to human RA is strongly supported by human and animal tests. It has many significant consequences for RA stratification, customized treatment and mitigation to recognise these causal ties and to understand that smoking is a potential mutual risk in both disorders.

Acknowledgements The authors express their thanks to the research team from the Department of Periodontics, Dr. HSRSM's Dental College and Hospital, Hingoli, Maharashtra, India for their support during data collection and manuscript preparation. The author did not receive any specific grant from funding agencies in the public, commercial, or not-for-profit sectors.

\section{References}

1. Weyand CM. New insights into the pathogenesis of rheumatoid arthritis. Rheumatology (Oxford). 2000;39(1):3-8.

2. Short CL. The antiquity of rheumatoid arthritis. Arthritis Rheum. 1974;17:193-205.

3. Snyderman R, MccCarty GA. Analogous mechanisms of tissue destruction in rheumatoid arthritis and periodontal disease. I. In: Genco RJ, Mergenhagen SE, editors. HosteParasite interaction in periodontal diseases; 1982. Washington, DC.

4. Mercado FB, Marshall RI, Bartold PM. Inter-relationships between rheumatoid arthritis and periodontal disease. A review $\mathrm{J}$ Clin Periodontol. 2003;30:761-72.

5. Hajishengallis G, Lamont RJ. Beyond the red complex and into more complexity: the polymicrobial synergy and dysbiosis (PSD) model of periodontal disease etiology. Mol Oral Microbiol. 2012;27:409-19. 
6. Gomes MS, Blattner TC, Filho MS, Grecca FS, Hugo FN, Fouad $\mathrm{AF}$, et al. Can apical periodontitis modify systemic levels of inflammatory markers? A systematic review and 6. meta-analysis. J Endod. 2013;39:1205-17.

7. Silman AJ, Pearson JE. Epidemiology and genetics of rheumatoid arthritis. Arthritis Res. 2002;4(3):265-72.

8. Mikuls TR, Payne JB, Deane KD, Thiele GM. Autoimmunity of the lung and oral mucosa in a multisystem inflammatory disease: The spark that lights the fire in rheumatoid arthritis? J Allergy Clin Immunol. 2016;137:28-34.

9. Mankia K, Emery P. Is localized autoimmunity the trigger for rheumatoid arthritis? Unravelling new targets for prevention. Discov Med. 2015;20:129-35.

10. Smolen JS, Aletaha D, McInnes IB. Rheumatoid arthritis. Lancet. 2016;388:2023-38.

11. Klareskog L, Lundberg K, Malmström V. Autoimmunity in rheumatoid arthritis: citrulline immunity and beyond. Adv Immunol. 2013;118:129-58.

12. Muller S, Radic M. Citrullinated autoantigens: from diagnostic markers to pathogenetic mechanisms. Clin Rev Allergy Immunol. 2015;49:232-9.

13. Trouw LA, Rispens T, Toes REM. Beyond citrullination: other post-translational protein modifications in rheumatoid arthritis. Nat Rev Rheumatol. 2017;13:331-9.

14. Wang S, Wang Y. Peptidylarginine deiminases in citrullination, gene regulation, health and pathogenesis. Biochim Biophys Acta. 2013;1829:1126-35.

15. Gyorgy B, Toth E, Tarcsa E, Falus A, Buzas EI. Citrullination: a posttranslational modification in health and disease. Int $\mathrm{J}$ Biochem Cell Biol. 2006;38:1662-77.

16. Makrygiannakis D, Hermansson M, Ulfgren AK, Nicholas AP, Zendman AJW, Eklund A, et al. Smoking increases peptidylarginine deiminase 2 enzyme expression in human lungs and increases citrullination in BAL cells. Ann Rheum Dis. 2008;67:1488-92.

17. Nesse W, Westra J, Jacqueline E, Abbas F, Nicholas AP, Vissink A, et al. The periodontium of periodontitis patients contains citrullinated proteins which may play a role in ACPA (anticitrullinated protein antibody) formation. J Clin Periodontol. 2012;39:599-607.

18. Bennike TB, Ellingsen T, Glerup H, Bonderup OK, Carlsen TG, Meyer MK, et al. Proteome analysis of rheumatoid arthritis gut mucosa. J Proteome Res. 2017;16:346-54.

19. Konig MF, Abusleme L, Reinholdt J, Palmer RJ, Teles RP, Sampson $\mathrm{K}$, et al. Aggregatibacter actinomycetemcomitans-induced hypercitrullination links periodontal infection to autoimmunity in rheumatoid arthritis. Sci Transl Med. 2016;8:369ra176.

20. Vossenaar ER, Zendman AJ, van Venrooij WJ, Pruijn GJ. PAD, a growing family of citrullinating enzymes: genes, features and involvement in disease. BioEssays. 2003;25:1106-18.

21. Arita K, Hashimoto H, Shimizu T, Nakashima K, Yamada M, Sato M. Structural basis for $\mathrm{Ca} 2+$-induced activation of human PAD4. Nat Struct Mol Biol. 2004;11:777-83.

22. Robertson WG, Marshall RW, Bowers GN. Ionised calcium in body fluids. Crit Rev Clin Lab Sci. 1981;15:85-125.

23. Potempa J, Mydel P, Koziel J. The case for periodontitis in the pathogenesis of rheumatoid arthritis. Nat Rev Rheumatol. 2017;13:606-20.

24. Hirsch HZ, Tarkowski A, Koopman WJ, Mestecky J. Local Production of IgA- and IgM-Rheumatoid Factors in Adult Periodontal Disease. J Clin Immunol. 1989;9(4):273-8.

25. Heasman LSF, Preshaw PM, McCracken GI, Hepburn S, Heasman PA. The effect of smoking on periodontal treatment response: a review of clinical evidence. J Clin Periodontol. 2006;33:241-53.
26. de Pablo P, Dietrich T, McAlindon TE. Association of periodontal disease and tooth loss with rheumatoid arthritis in the US population. J Rheumatol. 2008;35:70-6.

27. Marotte H, Farge P, Gaudin P, Alexandre C, Mougin B, Miossec $\mathrm{P}$. The association between periodontal disease and joint destruction in rheumatoid arthritis extends the link between the HLA-DR shared epitope and severity of bone destruction. Ann Rheum Dis. 2006;65:905-9.

28. Johansson L, Sherina N, Kharlamova N, Potempa B, Larsson B, Israelsson L, et al. Concentration of antibodies against Porphyromonas gingivalis is increased before the onset of symptoms of rheumatoid arthritis. Arthritis Res Ther. 2016;18:201.

29. Bello-Gualtero JM, Lafaurie GI, Hoyos LX, Castillo DM, DeAvila J, Munevar JC, et al. Periodontal disease in individuals with a genetic risk of developing arthritis and early rheumatoid arthritis: a cross-sectional study. J Periodontol. 2016;87:346-56.

30. Terao C, Asai K, Hashimoto M, Yamazaki T, Ohmura K, Yamaguchi A, et al. Significant association of periodontal disease with anticitrullinated peptide antibody in a Japanese healthy population - The Nagahama study. J Autoimmun. 2015;59:85-90.

31. Golub LM, Payne JB, Reinhardt RA, Nieman G. Can systemic diseases co-induce (not just exacerbate) periodontitis? A hypothetical "two-hit" model. J Dent Res. 2006;85:102-5.

32. Rosenstein ED, Greenwald RA, Kushner LJ, Weissmann G. Hypothesis: the humoral immune response to oral bacteria provides a stimulus for the development of rheumatoid arthritis. Inflammation. 2004;28:311-8.

33. Muller S, Radic M. Citrullinated autoantigens: from diagnostic markers to pathogenetic mechanisms. Clin. Rev. Allergy Immunol. 2015;49:232-39.

34. Michalowicz BS. Genetic and heritable risk factors in periodontal disease. J Periodontol. 1994;65(5):479-88.

35. Salvi GE, Yalda B, Collins JG, Jones BH, Smith FW, Arnold RR, Offenbacher S. Inflammatory mediator response as a potential risk marker for periodontal diseases in insulin-dependent diabetes mellitus patients. J Periodontol. 1997;68:127-35.

36. Ollier W, Thomson W. Population genetics of rheumatoid arthritis. Rheum Dis Clin North Am. 1992;18:741-59.

37. Bendtzen K, Morling N, Fomsgaard A, Svenson M, Jakobsen B, Odum N, Svejgaard A. Association between HLA-DR2 and production of tumour necrosis factor alpha and interleukin 1 by mononuclear cells activated by lipopolysaccharide. Scand J Immunol. 1988;28:599-606.

38. Bartold PM, Marshall RI, Haynes DR. Periodontitis and rheumatoid arthritis: A review. J Periodontol. 2005;76(11):2066-74.

39. Scardina GA, Messina P. Microvascular periodontal alterations: A possible relationship between perio dontitis and rheumatoid arthritis. Clin Hemor -heol Microcirc. 2007;37(2):29-35.

40. Yusof Z, Porter SR, Greenman J, Scully C. Levels of serum IgG against Porphyromonas gingivalis in patients with rapidly progressive periodontitis, rheumatoid arthritis and adult periodontitis. $\mathbf{J}$ Nihon Univ Sch Dent. 1995;37:197-200.

41. Yoshida A, Nakano Y, Yamashita Y, Oho T, Ito H, Kondo M, Ohishi M, Koga T. Immunodominant region of Actinobacillus actinomycetemcomitans 40-kilodalton heat shock protein in patients with rheumatoid arthritis. J Dent Res. 2001;80:346-50.

42. Moen K, Brun JG, Madland TM, Tynning T, Jonsson R. Immunoglobulin $\mathrm{G}$ and $\mathrm{A}$ antibody responsesto Bacteroides forsythus and Prevotella inter media in sera and synovial fluids of arthritis patients. Clin Diagn Lab Immunol. 2003;10:1043-50.

43. Ogrendik M, Kokino S, Ozdemir F, Bird PS, Hamlet S. Serum antibodies to oral anaerobic bacteria in patients with rheumatoid arthritis. Medscape Gen Med. 2005;7(2):2.

44. Moen K, Brun JG, Valen M, Skartveit L, Eribe EK, Olsen I, Jonsson R. Synovial inflammation in active rheumatoid arthritis 
and psoriatic arthritis facilitates trapping of a variety of oral bacterial DNAs. Clin Exp Rheumatol. 2006;24:656-63.

45. Di Benedetto A, Gigante I, Colucci S, Grano M. Periodontal disease: linking the primary inflammation to bone loss. Clin Dev Immunol. 2013;503754.

46. Uehara A, Imamura T, Potempa J, Travis J, Takada H. Gingipains from Porphyromonas gingivalis synergistically induce the production of proinflammatory cytokines through protease-activated receptors with Toll-like receptor and NOD1/2 ligands in human monocytic cells. Cell Microbiol. 2008;10:1181-9.

47. Chukkapalli S, Rivera-Kweh M, Gehlot P, Velsko I, Bhattacharyya I, Calise SJ, et al. Periodontal bacterial colonization in synovial tissues exacerbates collagen-induced arthritis in B10. RIII mice Arthritis Res Ther. 2016;18:161.

48. Quirke AM, Fisher BA, Kinloch AJ, Venables PJ. Citrullination of autoantigens: upstream of TNF $\alpha$ in the pathogenesis of rheumatoid arthritis. FEBS Lett. 2011;585:3681-8.

49. Harvey GP, Fitzsimmons TR, Dhamarpatni AASSK, Marchant C, Haynes DR, Bartold PM. Expression of peptidylarginine deiminase-2 and -4 , citrullinated proteins and anti-citrullinated protein antibodies in human gingiva. J Periodontal Res. 2013;48:252-61.

50. Quirke AM, Lugli EB, Wegner N, Hamilton BC, Charles P, Chowdhury M, et al. Heightened immune response to autocitrullinated Porphyromonas gingivalis peptidylarginine deiminase: a potential mechanism for breaching immunologic tolerance in rheumatoid arthritis. Ann Rheum Dis. 2014;73:263-9.

51. Laugisch O, Wong A, Sroka A, Kantyka T, Koziel J, Neuhaus K, et al. Citrullination in the periodontium - a possible link between periodontitis and rheumatoid arthritis. Clin Oral Investig. 2016;20:675-83.

52. Tolo K, Jorkjend L. Serum antibodies and loss of periodontal bone in patients with rheumatoid arthritis. J ClinPeriodontol. 1990;17:288-91.

53. Risheim H, Kjaerheim V, Arneberg P. Improvement of oral hygiene in patients with rheumatoid arthritis. Scand J Dent Res. 1992;100:172-5.

54. Mercado F, Marshall RI, Klestov AC, Bartold PM. Is there a relationship between rheumatoid arthritis and periodontal disease? J ClinPeriodontol. 2000;127:267-72.

55. Mercado FB, Marshall RI, Klestov AC, Bartold PM. Relationship between rheumatoid arthritis and periodontitis. J Periodontol. 2001;72:779-87.

56. Ramamurthy NS, Greenwald RA, Celiker MY, Shi EY. Experimental arthritis in rats induces biomarkers of periodontitis which are ameliorated by gene therapy with tissue inhibitor of matrix metalloproteinases. J Periodontol. 2005;76:229-33.

57. Lipsky PE, et al. Rheumatoid arthritis. In: Wilson JD, Braunwald E, Isselbacher KJ, et al., editors. Harrison's Principles of Internal Medicine. 12th ed. New York: McGraw- Hill; 1991. p. 1437-43.

58. Williams RC, Jeffcoat MK, Howell TH. Altering the progression of human alveolar bone loss with the non-steroidal antiinflammatory drug flurbiprofen. J Periodontol. 1989;60:485-90.

59. Novak MJ, Polson AM, Freeman E. Effects of gold salts on experimental periodontitis. I. Histometric evaluation of periodontal destruction. J Periodontol. 1984:55:69-77.

60. Golub LM, McNamara TF, D'Angelo G, Greenwald RA, Ramamurthy NSA. non-antibacterial chemically modified tetracycline inhibits mammalian collagenase activity. J Dent Res. 1987;66:1310-4.

61. Preshaw PM, Hefti AF, Novak MJ, Michalowicz BS, Pihlstrom BL, Schoor R, et al. Subantimicrobial dose doxycycline enhances the efficacy of scaling and root planing in chronic periodontitis: A multicenter trial. J Periodontol. 2004;75:1068-76.

62. LeResche L. The role of stress in inflammatory disease, including periodontal disease: review of concepts and current findings. Periodontol. 2000;2002(30):91-103.
63. Elliott JR, Paulsen GA, Mallek JA, et al. Treatment of early sero-positive rheumatoid arthritis: Doxycycline with methotrexate versus methotrexate alone. Arthritis Rheum. 2003;48:S654.

64. Assuma R, Oates T, Cohran D, Amar S, Graves DT. IL- 1 and TNF antagonists inhibit the inflammatory response and bone loss in experimental periodontitis. J Immunol. 1998;160:403-9.

65. Khare N, Vanza B, Sagar D, Saurav K, Chauhan R, Mishra S. Nonsurgical periodontal therapy decreases the severity of rheumatoid arthritis: a case- control study. J Contemp Dent Pract. 2016;17:484-8.

66. Romero-Sanchez C, Rodriguez C, Santos-Moreno P, Mesa AM, Lafaurie GI, Giraldo S, et al. Is the treatment with biological or non-biological DMARDS a modifier of periodontal condition in patients with rheumatoid arthritis? Curr Rheumatol Rev. 2017.

67. Kirchner A, Jäger J, Krohn-Grimberghe B, Patschan S, Kottmann $\mathrm{T}$, Schmalz G, et al. Active matrix metalloproteinase- 8 and periodontal bacteria depending on periodontal status in patients with rheumatoid arthritis. J Periodontal Res. 2017;52(4):745-54.

68. Mikuls TR, Payne JB, Yu F, Thiele GM, Reynolds RJ, Cannon GW, et al. Periodontitis and Porphyromonas gingivalis in patients with rheumatoid arthritis. Arthritis Rheum. 2014;66:1090-100.

69. Seror R, Le Gall-David S, Bonnaure-Mallet M, Schaeverbeke T, Cantagrel A, Minet J, et al. Association of anti-Porphyromonas gingivalis antibody titers with nonsmoking status in early rheumatoid arthritis: Results from the prospective French cohort of patients with early rheumatoid arthritis. Arthritis Rheumatol. 2015;67:1729-37.

70. Silosi I, Cojocaru M, Foia L, Boldeanu MV, Petrescu F, Surlin P, et al. Significance of circulating and crevicular matrix metalloproteinase-9 in rheumatoid arthritis- chronic periodontitis association. J Immunol Res. 2015:1-6.

71. Kurgan Ş, Fentoğlu O, Önder C, Serdar M, Eser F, Tatakis DN, Günhan M, et al. The effects of periodontal therapy on gingival crevicular fluid matrix metalloproteinase-8, interleukin-6 and prostaglandin E2 levels in patients with rheumatoid arthritis. J Periodontal Res. 2016;51:586-955.

72. Kharlamova N, Jiang X, Sherina N, Potempa B, Israelsson L, Quirke AM, et al. Antibodies to Porphyromonas gingivalis indicate interaction between oral infection, smoking, and risk genes in rheumatoid arthritis etiology. Arthritis Rheum. 2016;68:604-13.

73. Shah A. Harrison's Principles of Internal Medicine (18th ed.). United States: McGraw Hill. 2012:2738.

74. Aletaha D, Neogi T, Silman AJ, Funovits J, Felson DT, Bingham CO, et al. 2010 Rheumatoid Arthritis classification criteria: an American College of Rheumatology/ European League Against Rheumatism collaborative initiative. Ann Rheum Dis. 2010;69(9):1580-8.

75. Arnett FC, Edworthy SM, Bloch DA, McShane DJ, Fries JF, Cooper NS, et al. The American Rheumatism Association 1987 revised criteria for the classification of rheumatoid arthritis. Arthritis Rheum. 1988;31(3):315-24.

76. Bullock J, Rizvi S.AA, Saleh AM, Ahmed SS, Do D.P, Ansari RA, et al. Rheumatoid Arthritis: A Brief Overview of the Treatment. Med Princ Pract. 2018;27:501-507.

77. Combe B, Landewe R, Daien CI, Hua C, Aletaha D, Gracia JMA, et al. 2016 update of the EULAR recommendations for the management of early arthritis. Ann Rheum Dis. 2017;76:948-59.

78. Liu D, Ahmet A, Ward L, Krishnamoorthy P, Mandelcorn ED, Leigh R, Brown JP, et al. A practical guide to the monitoring and management of the complications of systemic corticosteroid therapy. Allergy Asthma Clin Immunol. 2013;9:30.

79. Rein P, Mueller RB. Treatment with Biologicals in Rheumatoid Arthritis: An Overview. Rheumatol Ther. 2017;4:247-261.

80. den Broeder AA, van Herwaarden N, van den Bemt BJF. Therapeutic drug monitoring of biologicals in rheumatoid arthritis: a disconnect between beliefs and facts. Curr Opin Rheumatol. 2018;30:266-75. 
81. Tovey MG, Lallemand C. Immunogenicity and other problems associated with the use of biopharmaceuticals. Ther Adv Drug Saf. 2011;2:113-28.

82. Gay RD, Clarke AW, Elgundi Z, Domagala T, Simpson RJ, Le NB, et al. Anti-TNF $\alpha$ domain antibody construct CEP-37247: Full antibody functionality at half the size. MAbs. 2010;2:625-38.

83. Lis K, Kuzawińskaan O, Iskra EB. Tumor necrosis factor inhibitors - state of knowledge. Arch Med Sci. 2014;10:1175-85.

84. Perpétuo IP, Caetano-Lopes J, Rodrigues AM, Marques RM, Ponte C, Canhão H, et al. Effect of Tumor Necrosis Factor Inhibitor Therapy on Osteoclasts Precursors in Rheumatoid Arthritis. Biomed Res Int. 2017;2017:1-10.

85. Mann DL. Innate immunity and the failing heart: the cytokine hypothesis revisited. Circ Res. 2015;116:1254-68.

86. Curtis JR, Singh JA. The Use of Biologics in Rheumatoid Arthritis: Current and Emerging Paradigms of Care. Clin Ther. 2011;33:679-707.

87. Mok CC. Rituximab for the treatment of rheumatoid arthritis: an update. Drug Des Devel Ther. 2014;8:87-100.
88. Emer JJ, Claire W. Rituximab: A Review of Dermatological Applications. J Clin Aesthet Dermatol. 2009;2:29-37.

89. Rosman Z, Shoenfeld Y, Goddard GZ. Biologic therapy for autoimmune diseases: an update. BMC Med. 2013;11:88.

90. Gómez-Gómez GJ, Masedo A, Yela C, Martínez-Montiel MDP, et al. Current stage in inflammatory bowel disease: What is next? World J Gastroenterol. 2015;21:11282-303.

91. Hodge JA, Kawabata TT, Krishnaswami S, et al. The mechanism of action of tofacitinib - an oral Janus kinase inhibitor for the treatment of rheumatoid arthritis. Clin Exp Rheumatol. 2016;34:318-28.

92. Cada DJ, Demaris K, Levien TL, et al. Tofacitinib. Hosp Pharm. 2013;48:413-24.

Publisher's Note Springer Nature remains neutral with regard to jurisdictional claims in published maps and institutional affiliations. 